\title{
Adenosine triphosphate-sensitive potassium channels and cardiomyopathies (Review)
}

\author{
ZHONGWEI LIU ${ }^{1}$, HUI CAI ${ }^{2}$, YONGHUI DANG ${ }^{3}$, CHUAN QIU $^{4}$ and JUNKUI WANG ${ }^{1}$ \\ ${ }^{1}$ Department of Cardiology, Shaanxi Provincial People's Hospital, Xi'an, Shaanxi 710068; \\ ${ }^{2}$ Department of Anesthesiology, First Affiliated Hospital of Xi'an Jiaotong University; \\ ${ }^{3}$ College of Medicine and Forensics, Xi'an Jiaotong University School of Medicine, Xi'an, Shaanxi 710061, P.R. China; \\ ${ }^{4}$ Department of Biostatistics and Bioinformatics, School of Public Health and Tropical Medicine, \\ Tulane University, New Orleans 70112-2705, LA, USA
}

Received September 16, 2014; Accepted June 5, 2015

DOI: $10.3892 / \mathrm{mmr} .2015 .4714$

\begin{abstract}
Cardiomyopathies have been indicated to be one of the leading causes of heart failure. Though it was indicated that genetic defects, viral infection and trace element deficiency were among the causes of cardiomyopathy, the etiology has remained to be fully elucidated. Cardiomyocytes require large amounts of energy to maintain their normal biological functions. Adenosine triphosphate-sensitive potassium channels $\left(\mathrm{K}_{\text {АTP }}\right)$, composed of inward-rectifier potassium ion channel and sulfonylurea receptor subunits, are present on the cell surface and mitochondrial membrane of cardiac muscle cells. As metabolic sensors sensitive to changes in intracellular energy levels, $\mathrm{K}_{\text {ATP }}$ adapt electrical activities to metabolic challenges, maintaining normal biological functions of myocytes. It is implied that malfunctions, mutations and altered expression of $\mathrm{K}_{\text {АтP }}$ are associated with the pathogenesis of conditions including c hypertrophy, diabetes as well as dilated, ischemic and endemic cardiomyopathy. However, the current knowledge is only the tip of the iceberg and the roles of $\mathrm{K}_{\text {ATP }}$ in cardiomyopathies largely remain to be elucidated in future studies.
\end{abstract}

\section{Contents}

1. Introduction

2. Molecular structural properties of $\mathrm{K}_{\text {ATP }}$

3. Biological function and regulation of $\mathrm{K}_{\mathrm{ATP}}$

4. Distribution of $\mathrm{K}_{\mathrm{ATP}}$ in cardiac muscle

5. $\mathrm{K}_{\text {ATP }}$ and cardiomyopathies

6. $\mathrm{K}_{\text {ATP }}$ and secondary cardiomyopathies

7. Summary and perspectives

Correspondence to: Dr Junkui Wang, Department of Cardiology, Shaanxi Provincial People's Hospital, 256 Youyi West Road, Xi'an, Shaanxi 710068, P.R. China

E-mail: junkuiwang@yeah.net

Key words: cardiomyopathy, $\mathrm{K}_{\mathrm{ATP}}$ channels

\section{Introduction}

Adenosine triphosphate-sensitive potassium channels $\left(\mathrm{K}_{\mathrm{ATP}}\right)$, which are distributed throughout the body in tissue types including smooth muscle, brain, skeletal muscle and cardiac muscle, have been known for decades (1). The basic biological function of $\mathrm{K}_{\mathrm{ATP}}$ is to adjust cell activities to the metabolic status, and $\mathrm{K}_{\mathrm{ATP}}$ is situated at the crosstalk site between cell metabolism and membrane excitability. When encountering insufficient energy levels, the inwardly rectifying potassium channels of $\mathrm{K}_{\mathrm{ATP}}$ are activated by nucleotides in the presence of magnesium ions. Opening of the channels would result in hyperpolarization of the membrane, which was found to be cytoprotective under various pathophysiological conditions. Cardiomyopathy is among one of the leading causes of deterioration of cardiac function and even heart failure; however, to date, knowledge regarding the etiology and underlying mechanisms has remained limited. As cardiomyopathies are associated with metabolic disorders, studies on $\mathrm{K}_{\text {ATP }}$ may provide novel basic knowledge and treatment strategies for cardiomyopathies. The present review briefly summarized the functions of $\mathrm{K}_{\text {ATP }}$ with a focus on the current understanding of its role in cardiomyopathies.

\section{Molecular structural properties of $K_{\mathrm{ATP}}$}

$\mathrm{K}_{\text {АTP }}$ is generally accepted as a hetero-octameric complex composed of inward-rectifier potassium ion channel (Kir)6 and sulfonylurea receptor (SUR) subunits. Kir6 is a pore-forming unit, and is encoded by the KCNJ8 (for Kir6.1) (2) and KCNJI1 (for Kir6.2) genes (3). The regulatory SUR subunits belong to the family of the ATP binding cassette $(\mathrm{ABC})$, which are encoded by genes including $A B C C 8$ (for SUR1) and $A B C C 9$ (for SUR2) (4). Post-transcriptional modification by RNA splicing generates mainly two molecular variants of SUR, namely SUR2A and SUR2B, whose biophysiological characteristics vary distinctly $(5,6)$.

Biochemical and physiological studies suggested that the normal functional $\mathrm{K}_{\mathrm{ATP}}$ is supported and maintained by a $4: 4$ stoichiometric co-assembly of Kir6.2 and SUR1, or Kir6.2 and SUR2A (SUR2B) subunits $(7,8)$. This octamer arrangement 
implies that the genes of Kir and SUR may be co-regulated (9). Indeed, it was found that $K C N J 11$ and $A B C C 8$ share neighboring locations on human chromosome 11p15.1 (10); similarly, KCNJ8 and ABCC9 were located on human chromosome 12p12.1 adjacently (11).

The understanding of the structure of $\mathrm{K}_{\mathrm{ATP}}$ is mainly based on crystallographic studies on bacteria and eukaryotic cells (12). It was demonstrated that the main structure of the Kir channel was composed of two transmembrane M1 and M2 helices, which were connected by a bridge-like loop, favoring ion selection control and the generation of a narrow porous architecture (13). TMD1 and TMD2, which are six-helix transmembrane domains, put up the primary structure of the SUR sub-units (14). An accessory five-helix transmembrane TMD0 domain was found at the $\mathrm{N}$-terminus of SURs, having a role in gating and trafficking of the Kir6 sub-unit (15). Between TMD1 and TMD2, nucleotide binding fold (NBF), comprising NBF1 and NBF2, was identified in previous studies (16). An octameric structure composed of four Kir6.x and four SUR subunits was proposed (17); however, the specific physical contact, connection and interaction of the sub-units have remained to be fully elucidated.

\section{Biological function and regulation of $\mathbf{K}_{\mathrm{ATP}}$}

The signature sequence of potassium ion $\left(\mathrm{K}^{+}\right)$channels, which is ubiquitous among the $\mathrm{K}^{+}$channel family, is highly conserved in Kir sub-units, eliciting $\mathrm{K}^{+}$-selective properties (18). Rapid and reversible closure and activation accommodating to the metabolic status is the characteristic biological property of $\mathrm{K}_{\text {ATP }}$ (19). In the presence of ATP, non-hydrolysable ATP analogues or even adenosine diphosphate (ADP) with the absence of magnesium ions $\left(\mathrm{Mg}^{2+}\right)$, the channel activity is blocked and the channel is closed $(20,21)$, suggesting that the inactivation of $\mathrm{K}_{\text {ATP }}$ does not rely on phosphorylation and the binding relies on the gamma-phosphate of the ATP molecule (22). A binding pocket is formed by the $\mathrm{C}$ - and $\mathrm{N}$-termini residues in the plasma with three-dimensional folding $(23,24)$. There are four binding pockets for the octameric structure - one for each channel at each kir6 sub-unit $(25,26)$. Channel gating and ATP binding are linked via a helical structure, which was proposed to lie parallel to the interface of the membrane (27). The location of the contact point was suggested at the junction of the inner helix bundle $(28,29)$ (Fig. 1).

The SUR sub-unit regulates $K_{\text {ATP }}$ activity by interacting with $\mathrm{Mg}^{2+}$ adenosine nucleotides: ATP and ADP stimulate channel opening in the presence of $\mathrm{Mg}^{2+}$, while the nucleotides deactivate channel activity in the absence of $\mathrm{Mg}^{2+}(30)$. In the cytoplasm, composed of nucleotide-binding motifs, the NBFs (NBF1 and NBF2) have the main regulatory effect on $\mathrm{K}_{\text {ATP }}$ function. It was suggested that the dimerization of two NBFs was required for $\mathrm{Mg}^{2+}$-dependent ATP hydrolysis by SUR (31). The inhibition induced by ATP on the Kir6 sub-unit may be overcome by the hydrolytic activity of dimeric NBFs on ATP in the presence of $\mathrm{Mg}^{2+}(32)$. These regulatory effects of SUR on Kir6 gating are supported by a connecting structure named L0 linker, which is situated between the SUR TMD0 domain and the Kir6.2 cytoplasmic N-terminus (33).

Briefly, $\mathrm{K}_{\text {ATP }}$ regulation is characterized by fast and reversible deactivation and closure induced by cytoplasmic

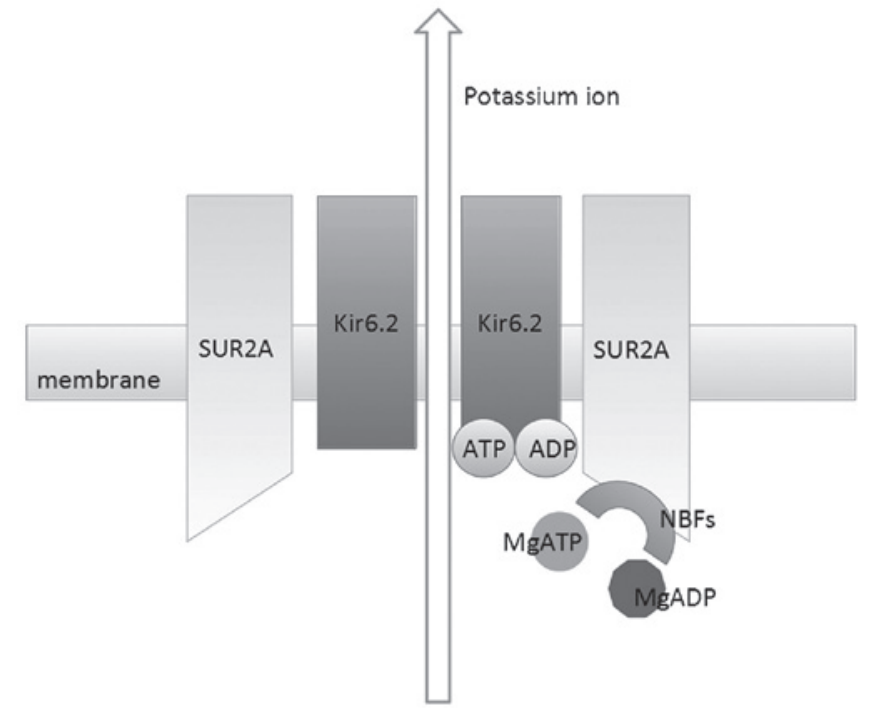

Figure 1. Schematic demonstration of the molecular structure and function of cardiac $\mathrm{K}_{\mathrm{ATP}}$ channels. 4 Kir6.2 subunits and 4 SUR2A subunits constitute the heterooctameric complex. $\mathrm{K}_{\mathrm{ATP}}$ activity is inhibited by ATP by direct binding to Kir6.2. In the absence of magnesium ions, ADP also inhibits channel activity even with lower binding affinity to Kir6.2. However, in the presence of magnesium ions, cytoplasmic ADP and ATP serve to stimulate channel activity by binding to NBF domains, which are located on SUR2A subunits. ATP, adenosine triphosphate; ADP, adenosine diphosphate; $\mathrm{K}_{\mathrm{ATP}}$, ATP-sensitive potassium channels; NBF, nucleotide binding fold; Kir, inward-rectifier potassium ion channel; SUR, sulfonylurea receptor.

nucleotide diphosphates and triphosphates. In intact cells, the $\mathrm{K}_{\mathrm{ATP}}$ is almost permanently inhibited by ATP, whose concentration is steadily maintained at a millimolar level $(1-5 \mathrm{mmol} / \mathrm{l})$, even while the cells undergo metabolic changes (34). Under such circumstance, by interaction with the SUR subunit, the channel is effectively activated by exogenous $\mathrm{Mg}^{2+}$ nucleotides, particularly MgADP (19). Nucleotide regulation is currently considered the key mechanism in controlling $\mathrm{K}_{\text {ATP }}$ opening, though several other regulators were also proposed in certain $\mathrm{K}_{\mathrm{ATP}}$-associated diseases.

\section{Distribution of $K_{\mathrm{ATP}}$ in cardiac muscle}

$K_{\text {ATP }}$ in cardiac sarcolemma. Previous studies confirmed that in hearts of rodents, SUR1 and Kir6.2 constitute atrial sarcolemmal $\mathrm{K}_{\mathrm{ATP}}(35)$, while ventricular sarcolemmal $\mathrm{K}_{\mathrm{ATP}}$ is mainly composed of SUR2A and Kir6.2 (36). Variants of SUR1 and SUR2A were identified in atrial as well as ventricular cardiac muscles in humans. Generally, under normal physiological conditions, the sarcolemmal $\mathrm{K}_{\mathrm{ATP}}$ remains a static status unless it encounters severe metabolic challenges, including anoxia, ischemia and metabolic toxic drugs $(37,38)$. Activated sarcolemmal $\mathrm{K}_{\text {ATP }}$ serves a cardioprotective role by inhibiting calcium overload, recovering contractility, preserving energy supply and stabilizing the membrane potential (39). Treatment with $\mathrm{K}_{\text {АTP }}$ openers, such as diazoxide, resulted in a decrease in the incidence of arrhythmias, including tachycardia and ventricular fibrillation (40).

$K_{A T P}$ in cardiac mitochondria. Except for the sarcolemmal $\mathrm{K}_{\mathrm{ATP}}, \mathrm{K}_{\mathrm{ATP}}$ distributed in cardiac mitochondria (mitoK $\mathrm{K}_{\mathrm{ATP}}$ ) are also considered important in cardiac pathophysiology. To date, 
the molecular composition of mitoK $\mathrm{ATP}_{\mathrm{P}}$ has remained elusive. It was proposed that the heterogenous integration of SUR1 and Kir6.1 properly represents the properties of mitoK ${ }_{\text {АTP }}(41)$; however, in Kir6.1 and Kir6.2 knockout animals, the activity of mitoK ${ }_{\text {ATP }}$ remained unaffected (42). Several studies have assessed the canonical composition of SUR and Kir6 molecules in the mitoK $\mathrm{ATP}_{\mathrm{A}}$ structure. In mitochondrial extracts, protein detected with anti-Kir6.1 antibody was proved not to be Kir6.1 by subsequent mass spectrometric analysis (43). In another study, an NBF1 domain, which was specifically localized to mitochondria, and the lack of a SUR2 sub-unit protein were identified in myocytes (44).

Unlike the indeterminacy of its structure, the basic function of mitoK ${ }_{\text {ATP }}$ is relatively clear in the heart, though it is not completely understood. Under stress induced by multiple stimuli, efficient energy transfer from mitochondria to cytosol is guaranteed by mitoK $\mathrm{K}_{\mathrm{ATP}}$ activation. Extrinsic stressful signals, including reactive oxygen species, transduced across the cytosol to the mitochondria, may induce the activation of mitoK $_{\text {ATP }}$, whose opening would decrease opening of the mitochondrial permeability transition (MPT) pore, which would result in myocyte death (45).

\section{5. $K_{\mathrm{ATP}}$ and cardiomyopathies}

Cardiomyopathy was defined by the World Health Organization as cardiac diseases accompanied by cardiac dysfunction. Dilated cardiomyopathy (DCM), hypertrophic cardiomyopathy (HCM), restrictive cardiomyopathy (RCM), arrhythmogenic right ventricular cardiomyopathy and secondary cardiomyopathy are accepted as types of cardiomyopathy. It is considered that energetic and metabolic disorders are involved in pathophysiological processes of cardiomyopathy, which is highly associated with cardiac $\mathrm{K}_{\mathrm{ATP}}$ as mentioned above.

$K_{A T P}$ and HCM. HCM is characterized by unexplained and asymmetric left ventricular hypertrophy without explicit causes and includes coronary heart disease, arterial stenosis, hypertension, valvular heart disease and further systemic diseases that induce left ventricular hypertrophy (46). Heart failure, sudden cardiac death (SCD) and stroke are the common clinical manifestations in patients with HCM, which is often diagnosed by echocardiography showing a maximal left ventricular wall thickness of $\geq 15 \mathrm{~mm}$. Myocyte malalignment, myocyte hypertrophy and myocardial interstitial fibrosis are the main histological features of HCM (47).

Imbalances in energy metabolism were suggested to be the underlying cause of the occurrence and development of HCM, corresponding with mitochondrial dysfunction and biophysical disorganization in HCM. In response to energetic metabolic deficiency, myocyte hypertrophy may be the compensatory consequence. As $\mathrm{K}_{\text {ATP }}$ are highly involved in energy metabolism, they may be implicated in HCM development (48).

Mechanistic assays using $\mathrm{K}_{\mathrm{ATP}}$ antagonists or activators were performed to testify the role of $\mathrm{K}_{\mathrm{ATP}}$ in HCM. Hypertrophic myocytes were acquired from spontaneously hypertensive rats (SHR) by Sodder et al (49). Trypsin, which was able to re-activate $\mathrm{K}_{\mathrm{ATP}}$, only increased $\mathrm{K}_{\mathrm{ATP}}$ channel activity by $29 \%$ in hypertrophic myocytes as opposed to $63 \%$ in the control, indicating that $\mathrm{K}_{\mathrm{ATP}}$ activity loss was involved in the pathogenesis of cardiac hypertrophy. In another study by Rajesh et al (50), ischemic pre-conditioning (IP) was demonstrated to have protective effects against supra-renal transverse abdominal aortic constriction-induced cardiac hypertrophy. 5-hydroxydecanoic acid (5-HD), a specific $\mathrm{K}_{\mathrm{ATP}}$ antagonist, was applied to animals after IP. The results showed that 5-HD pre-treatment impaired the protective effects of IP during sustained cardiac ischemia in hypertrophied hearts (50). In another study, the induction of hypertrophy in cultured ventricular myocytes by alpha1 adrenoceptor agonist phenylephrine (PE) was evidenced by increased cell size, elevated expression of myosin light chain-2 and atrial natriuretic peptide (51). Diazoxide, as one of the canonical mitoK ${ }_{\text {ATP }}$ openers, almost completely prevented the hypertrophic inductive effects of PE.

Numerous previous studies provided direct evidence for the protective role of $\mathrm{K}_{\mathrm{ATP}}$ in cardiac hypertrophy. By partial ligation of the ascending aorta, Yuan et al (52) created an animal model of left ventricular hypertrophy. Responsiveness of $\mathrm{K}_{\text {ATP }}$ to ATP (exogenous as well as locally generated ATP) in isolated myocytes from hypertrophic hearts was found to be markedly decreased in a patch clamp assay (52). In a study investigating hearts from SUR2-knockout mice, a significantly greater heart size and ventricular mass were identified (53). Shimokawa et al (54) found that in endocardial cells isolated from hypertrophied hearts of SHR, the $\mathrm{K}_{\text {ATP }}$ channel currents were significantly smaller and the time required to reach peak currents after the onset of $\mathrm{K}_{\text {ATP }}$ channel opening was significantly longer than that in the control group. Furthermore, the dysfunctional $\mathrm{K}_{\mathrm{ATP}}$ failed to respond rapidly to exogenous ATP. These results indicated that biophysiologically dysfunctional $\mathrm{K}_{\text {ATP }}$ may contribute to cardiac hypertrophy.

The possible underlying mechanisms of $\mathrm{K}_{\text {ATP }}$ impairment and HCM were investigated by several studies. Heart hypertrophy was achieved in a rat model of pressure overload, which was achieved by abdominal aortic banding (55). A $K_{\text {ATP }}$ opener, iptakalim, was applied orally to rats, which reversed the deteriorating cardiac function hemodynamically and histologically, as well as the serum content of B-type natriuretic peptide. After $\mathrm{K}_{\text {ATP }}$ activation, the potassium efflux facilitated calcium influx to increase calcium concentration, which activated endothelial nitric oxide synthase (eNOS) via the calcium-calmodulin pathway. eNOS then catalyzed the biological synthesis of endogenous NO. Thus, indirectly, the activation of $\mathrm{K}_{\mathrm{ATP}}$ led to the maintenance of cardiac function and hemodynamic homeostasis by modulation of NO production (55). In chronic transverse aortic constriction-induced cardiac hypertrophied $\mathrm{K}_{\mathrm{ATP}}$-disrupted rats, the expression of PPAR gamma co-activator-1 alpha (PGC-1alpha) was significantly decreased (56). It was thought that PGC-1alpha had an important role in regulating energetic metabolism through mitochondrial enzymes during exposure to cardiac pressure overload. The transcription of PGC-1 alpha was activated by phosphorylated forkhead box protein O1 (FOXO1), whose phosphorylation was reported to proceed through activation of Akt. In addition, it was observed that the $\mathrm{K}_{\mathrm{ATP}}$ channel dysfunction induced by SUR1 disruption and Kir6.2 knockout resulted in an overall decrease in FOXO1 expression (56). The study indicated that FOXO1/PGC-1alpha signaling was one of the possible mechanisms of sarcolemmal $\mathrm{K}_{\mathrm{ATP}}$-associated cardiac hypertrophy. 

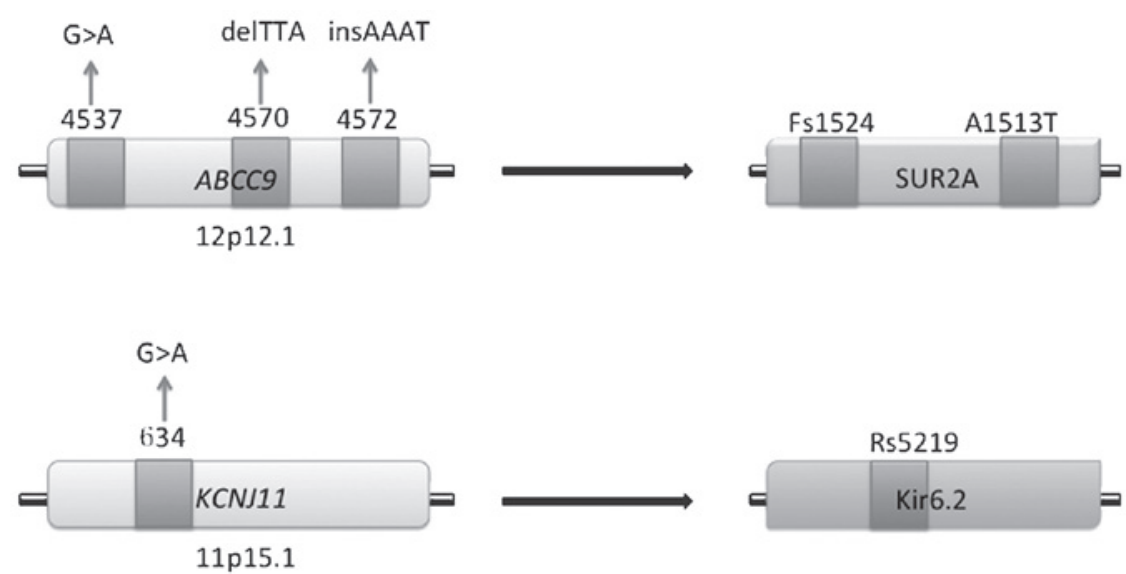

Figure 2. Mutations of $\mathrm{K}_{\text {ATP }}$ sub-unit genes correlated with dilated cardiomyopathy. Mutations in $A B C C 9$ gene comprise a mis-sense mutation at site 4,537, a three-base pair deletion at site 4,572 and a four-base pair insertion mutation at site 4,570-4,572. These mutations lead to a frameshift at site 1,524 and amino acid substitution at site 1,513 of the SUR2A sub-unit. In the KCNJ11 gene, a non-synonymous mutation at site 634 causes amino acid replacement at site 5,219 of the Kir6.2 sub-unit. Fs, frameshift; A, amino acid substitution; Rs, acid replacement; Kir, inward-rectifier potassium ion channel; SUR, sulfonylurea receptor.

$K_{A T P}$ and dilated cardiomyopathy. As another important type of cardiomyopathy, DCM is clinically characterized by ventricular dilation and impaired contractility, often leading to heart failure and SCD (3). As myocardial mass and volume increase, the ventricular wall often becomes thin and stretched (57). To date, the etiology of DCM has remained to be fully elucidated. DCM may occur secondary to heart diseases, including congenital heart disease, valvular heart disease, ischemic heart disease, viral myocarditis and Chagas disease (58). Of note, it is now widely accepted that DCM is highly genetic. Mutations of $\mathrm{K}_{\mathrm{ATP}}$-associated genes were confirmed to be involved in the etiology of DCM.

Bienengraeber et al (59) identified two mutations in the ABCC 9 gene encoding the $\mathrm{K}_{\text {ATP }}$ sub-unit SUR2A by genomic DNA scanning in patients with dilated cardiomyopathy with tachycardia (DCM10). One mutation was described as a three-base pair deletion and a four-base pair insertion mutation (4,570-4,572delTTAinsAAAT), which introduced four abnormal terminal residues followed by a premature stop codon and caused a frameshift at Leu1524 (Fs1524) after translation. Another mutation was suggested as a missense mutation $(4,537 \mathrm{G}>\mathrm{A})$, causing an $\mathrm{A} 1,513 \mathrm{~T}$ amino acid substitution as occurring at the $\mathrm{C}$ terminus of SUR2A and leading to a disruption of the normal organization of the NBD2 pocket. Reduced $\mathrm{K}_{\text {ATP }}$ channel trafficking, aberrant $\mathrm{K}_{\mathrm{ATP}}$ channel gating and an anomalous intrinsic ATP hydrolysis cycle were observed when the SUR2 sub-unit was defective and co-expressed with the Kir6.2 sub-unit (59). Thus, the mediation between energetic and electrical signals by $\mathrm{K}_{\mathrm{ATP}}$ is impaired in DCM. Patients with the abovementioned genetic mutations may therefore be considered to have an increased susceptibility to DCM.

A study using Langendorff hearts extracted from patients diagnosed with DCM revealed that the expression of the Kir6 sub-unit (Kir6.1 as well as Kir6.2) changed correspondingly with that of the SUR sub-unit (SUR1 as well as SUR2A) in the endocardium and epicardium (60). This result indicated that the other sub-unit, Kir6, may also have a role as one of the etiological factors of DCM. The results of a study on KCNJ11 gene knockout hearts exposed to hemodynamic overload showed that these hearts were more susceptible to maladaptive remodeling and congestive heart failure (59). When under imposed overload stress, KCNJ11-null mutant hearts were markedly dilated and inefficient regarding their contractility, sharing common features with CMD10 (61). Indeed, after the deficiency of Kir6.2 was compensated by embryonic stem cell therapy, the cardiac function was partially restored (62). Recently, KCNJ11 gene mutation was also suggested to be one of the causes of DCM. A gene polymorphism called E23K, which is a non-synonymous mutation occurring at codon 23 of the KCNJ11 gene $(634 \mathrm{G}>\mathrm{A})$, led to the replacement of a glutamic acid residue by a lysine at this polymorphic site (rs5219) at the Kir6.2 sub-unit (63). By analyzing the blood of patients with DCM, Xi et al (64) discovered that this mutation was highly associated with the left ventricular end diastolic dimension (LVEDD) and left atrial dimension (LAD), which markedly increases in DCM (64) (Fig. 2).

\section{6. $K_{\text {ATP }}$ and secondary cardiomyopathies}

$K_{\text {ATP }}$ and ischemic cardiomyopathy (ICM). Due to the high and increasing morbidity of coronary heart disease, ICM is now considered to be one of the most common underlying causes of heart failure in modern-day society (65). As a result of sustained myocardial ischemia, ICM is characterized by marked loss of contractile units in the myocardium. Ischemia and accompanied re-perfusion injury may lead to myocyte apoptosis and myocardial necrosis.

Several previous studies have examined the correlation between myocyte apoptosis and $\mathrm{K}_{\text {ATP }}$ under ischemia/re-perfusion conditions. They posed the hypothesis that $\mathrm{K}_{\text {ATP }}$ exerts its anti-apoptotic effects upon activation. Indeed, the role of $\mathrm{K}_{\mathrm{ATP}}$ in cellular calcium signal regulation may have a preventive effect against cardiac apoptosis (66). Calcium overload, which refers to the accumulation of calcium ions in the cell matrix, is one of the mechanisms triggering apoptosis. As the concentration of calcium ions rises in the mitochondria, the opening of the MPT pore becomes irreversible. Pro-apoptotic proteins, such as cytochrome $\mathrm{C}$, are subsequently released to 


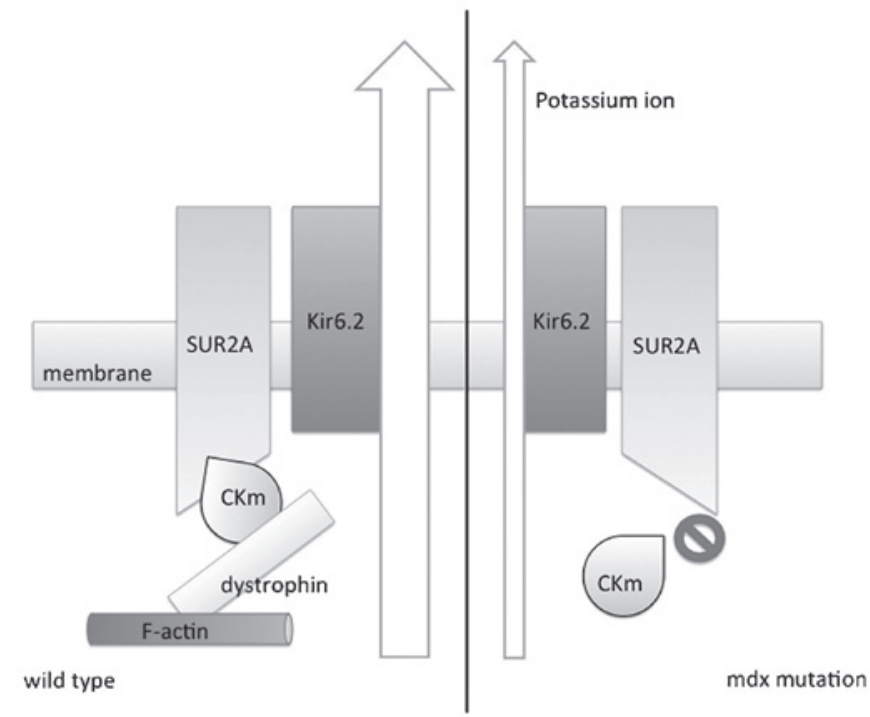

Figure 3. Possible mechanism of cardiomyopathy in Duchenne muscular dystrophy. The left part of the figure shows the activation of $\mathrm{K}_{\mathrm{ATP}}$ in the heart of normal controls. With the regulation of $\mathrm{CKm}$, normal activity and function of $\mathrm{K}_{\text {ATP }}$ are maintained. The right part of this figure shows the inhibition of $\mathrm{K}_{\mathrm{ATP}}$ in hearts of mdx-mutant mice deficient of dystrophin, probably leading to loss of activity of $\mathrm{K}_{\mathrm{ATP}}$. CKm, creatine kinase muscle isoform; Kir, inward-rectifier potassium ion channel; SUR, sulfonylurea receptor.

induce apoptosis. However, after being activated, $\mathrm{K}_{\text {ATP }}$ opens to allow potassium ion influx into the cell matrix to depolarize the inner membrane, thus reducing the calcium uptake of the matrix (67).

Furthermore, previous studies implied that inflammation is involved in coronary artery disease and myocardial ischemia. During this process, inflammatory cytokines, including interleukin-1 (IL-1), IL-6 and tumor necrosis factor-alpha (TNF-alpha) were released (68). Through interacting with TNF receptors, TNF-alpha potently induced cell apoptosis through death receptor- or caspase cascade-mediated apoptotic pathways (69). Zhou et al (70) reported that the opening of $\mathrm{K}_{\mathrm{ATP}}$ reduced TNF-alpha production by inhibiting its downstream protein mitogen-activated protein kinase (70). Thus, the anti-apoptotic effects of cardiac $\mathrm{K}_{\mathrm{ATP}}$ in ICM may be based on its abilities to modulate inflammation.

$K_{A T P}$ and cardiomyopathy in Duchenne muscular dystrophy $(D M D)$. It is generally accepted that DMD is an X-linked progressive neuromuscular disorder with the manifestation of generalized muscular weakness and wasting. Patients with DMD are often diagnosed at 6-8 years of age and die of respiratory or cardiac failure by the age of 30 years in most cases (71). The dystrophin gene, which is located at the short arm of the $\mathrm{X}$ chromosome at cytogenetic band 21 (Xp21), was suggested to be the leading cause of DMD. Mutations of this gene lead to the expression of mutant dystrophin protein within myofibers throughout all types of muscle cell, including smooth, skeletal and cardiac muscle cells. A lethal form of cardiomyopathy occurs in the majority of DMD patients, which is characterized by ventricular wall thickness reduction and cardiac chamber enlargement (72).

Graciotti et al (73) reported that cardiac $\mathrm{K}_{\mathrm{ATP}}$ has an important role in cardiomyopathy in DMD and proposed a possible regulatory mechanism. Importantly, the study reported that in myocytes from normal mice, $\mathrm{K}_{\mathrm{ATP}}$ sub-unit Kir6.2 and dystrophin were physically connected, sharing the same location on the t-tube. Furthermore, a metabolic enzyme, creatine kinase muscle isoform $(\mathrm{CKm})$, which was described as a regulator of $\mathrm{K}_{\mathrm{ATP}}$ activity, was also in physical contact with dystrophin. In mdx mutant mice, which were deficient of the full length of dystrophin, CKm membrane localization was disrupted (73). This result suggested that dystrophyin may act as a scaffold allowing $\mathrm{K}_{\mathrm{ATP}}$ and its regulatory proteins to form a complex, coordinating metabolic regulation. Thus, when dystrophin was absent in DMD, loss of CKm interaction led to the disruption of its modulation of $\mathrm{K}_{\mathrm{ATP}}$ channel activity, resulting in a disability of $\mathrm{K}_{\mathrm{ATP}}$ in sensing the intracellular ATP concentration (Fig. 3).

$K_{A T P}$ and diabetic cardiomyopathy $(D b C M)$. In patients with diabetes mellitus, almost every tissue type is affected by metabolic disorders, resulting in vital organ dysfunctions. It was reported that cardiovascular diseases take responsibility for $\sim 65 \%$ of diabetes-associated mortality (74). Myocardial dysfunction occurring without evidence of any other primary heart disease, including coronary artery disease and valvular heart disease, is now generally defined as DbCM.

The association between diabetes and $\mathrm{K}_{\mathrm{ATP}}$ has been known for several years. Gloyn et al (75) launched a case-control study on 2,486 diabetes patients in the United Kingdom, showing that $\mathrm{KCNJ11}$ gene polymorphism E23K was associated with type 2 diabetes. In addition, in the Walker B motif of NBD2 of SUR sub-units, a mutation of the conserved glutamate catalytic residue (E1506) to lysine (E1506K) resulted in reduced $\mathrm{K}_{\mathrm{ATP}}$ channel activation in beta cells, which was detected in patients with neonatal diabetes. This mutation was therefore thought to be one of the causes of neonatal diabetes (76).

Based on these results, studies on $\mathrm{K}_{\mathrm{ATP}}$ in cardiomyocytes may be of potential significance to reveal the underlying mechanisms of DbCM. To date, only a few studies on this association are available; however, the results are of importance. Fancher et al (77) evaluated the function and expression of mitoK ${ }_{\text {ATP }}$ in the hearts of mice with type 1 diabetes. The expression of Kir6.1 and SUR1 was found decreased in interfibrillar mitochondria, while the expression of Kir6.1 was found to be reduced in sub-sarcolemmal mitochondria in diabetic rat hearts (77). Furthermore, the expression of Kir6.2 and SUR2A was significantly decreased in diabetic rats, which could be restored by correction of hyperglycemia. Of note, diazoxide, a $\mathrm{K}_{\text {ATP }}$ opener, showed cardioprotective effects (78).

$K_{A T P}$ and Keshan disease $(K D) . \mathrm{KD}$ initially drew attention in 1930s by its outbreak in Keshan County in northeast China. The heart is the primary target organ of KD (79). Enlarged heart, cardiac arrhythmia, cardiogenic shock and congestive heart failure are the clinical manifestations of KD. It was recognized as a form of cardiomyopathy, which was histologically characterized by multifocal necrosis and cardiac fibrosis (80). $\mathrm{KD}$ is endemic as it is limited to certain geographical areas and with seasonal variations. Though the etiology of KD still remains to be fully elucidated, selenium deficiency is considered the major cause, as selenium deficiency in local residents and food were significantly associated with the geographical distribution of KD (81). 
A previous study by our group reported that cardiac function was significantly impaired in selenium-deficient rats (82). At the same time, the expression of the two sub-units of $\mathrm{K}_{\mathrm{ATP}}$, Kir6.2 and SUR2A, was inhibited in myocytes, accompanied by a decrease of glutathione peroxidase, which indicated the occurrence of oxidative stress (82). After introduction of oxidative stress, the activity of mitoK $_{\mathrm{ATP}}$ was upregulated according to a study by Pereira et al (83). They concluded that $\mathrm{K}_{\text {ATP }}$ acted as a molecular sensor for oxidative stress, whose activation helped to reduce free-radical generation in the mitochondrial respiratory chain. However, the study did not continue to observe the activity of mitoK ${ }_{\text {ATP }}$ during sustained and severe oxidative stress, which may have induced significant mitochondrial dysfunction, and the activity and expression of mitoK $_{\text {АTP }}$ may have been jeopardized under these conditions. Further study regarding oxidative stress, $\mathrm{K}_{\text {АTP }}$ and cardiac dysfunction in KD is still required.

\section{Summary and perspectives}

As a mediator in cellular metabolism, $\mathrm{K}_{\text {ATP }}$ couples the energetic status to the excitability of the cell membrane, sensing metabolic changes and leading to morphological changes as well as secondary signaling. $\mathrm{K}_{\text {ATP }}$ channels are distributed in the cytosol and mitochondria of cardiomyocytes. As one of the leading causes of heart failure, cardiomyopathy is characterized by metabolic challenges, which could be alleviated by activation of $\mathrm{K}_{\text {ATP. }}$. Dysfunction and deficiency of cardiac $\mathrm{K}_{\mathrm{ATP}}$ were suggested to have important roles in primary cardiomyopathies, including hypertrophic cardiomyopathy and dilated cardiomyopathy, as well as secondary cardiomyopathies, including ischemic cardiomyopathy, diabetic cardiomyopathy, endemic cardiomyopathy and cardiomyopathy in Duchenne muscular dystrophy.

Due to the lack of sufficient knowledge regarding $\mathrm{K}_{\mathrm{ATP}}$ in cardiomyopathies, numerous questions remain: Do $\mathrm{K}_{\mathrm{ATP}}$ channels share unitary features in the occurrence and development of different types of cardiomyopathies? Are there any unique changes of $\mathrm{K}_{\mathrm{ATP}}$ specific for each type of cardiomyopathy? What are the polymorphisms of the gene encoding $\mathrm{K}_{\text {ATP }}$ in other primary cardiomyopathies, including restrictive cardiomyopathy and arrhythmogenic right ventricular cardiomyopathy? Is $\mathrm{K}_{\text {АтP }}$ involved in gene-environmental interactions in endemic cardiomyopathies? To address these questions, further studies on $\mathrm{K}_{\text {ATP }}$ in cardiomyopathies should be implemented in the future.

\section{Acknowledgements}

The present review was fully supported by the National Natural Science Foundation of China (grant nos. 81371473 and 81171262).

\section{References}

1. Rapposelli S: Novel adenosine 5'-triphosphate-sensitive potassium channel ligands: a patent overview (2005-2010). Expert Opin Ther Pat 21: 355-379, 2011.

2. Delaney JT, Muhammad R, Blair MA, Kor K, Fish FA, Roden DM and Darbar D: A KCNJ8 mutation associated with early repolarization and atrial fibrillation. Europace 14: 1428-1432, 2012.
3. Yamada S, Kane GC, Behfar A, Liu XK, Dyer RB, Faustino RS, Miki T, Seino S and Terzic A: Protection conferred by myocardial ATP-sensitive $\mathrm{K}^{+}$channels in pressure overload-induced congestive heart failure revealed in KCNJ11 Kir6.2-null mutant. J Physiol 577: 1053-1065, 2006.

4. Fatima N, Schooley JF Jr, Claycomb WC and Flagg TP: Promoter DNA methylation regulates murine SUR1 (Abcc8) and SUR2 (Abcc9) expression in HL-1 cardiomyocytes. PLoS One 7: e41533, 2012.

5. Shi Y, Wu Z, Cui N, Shi W, Yang Y, Zhang X, Rojas A, Ha BT and Jiang C: PKA phosphorylation of SUR2B subunit underscores vascular $\mathrm{K}_{\text {ATP }}$ channel activation by beta-adrenergic receptors. Am J Physiol Regul Integr Comp Physiol 293: R1205-R1214, 2007.

6. Zhou M, He HJ, Suzuki R, Liu KX, Tanaka O, Sekiguchi M, Itoh $\mathrm{H}$, Kawahara $\mathrm{K}$ and Abe $\mathrm{H}$ : Localization of sulfonylurea receptor subunits, SUR2A and SUR2B, in rat heart. J Histochem Cytochem 55: 795-804, 2007.

7. Shyng S and Nichols CG: Octameric stoichiometry of the $\mathrm{K}_{\text {ATP }}$ channel complex. J Gen Physiol 110: 655-664, 1997.

8. Nakaya $\mathrm{H}$ : Role of ATP-sensitive $\mathrm{K}^{+}$channels in cardiac arrhythmias. J Cardiovasc Pharmacol Ther 19: 237-243, 2014.

9. Kang Y, Ng B, Leung YM, He Y, Xie H, Lodwick D, Norman RI, Tinker A, Tsushima RG and Gaisano HY: Syntaxin-1A actions on sulfonylurea receptor $2 \mathrm{~A}$ can block acidic $\mathrm{pH}$-induced cardiac K(ATP) channel activation. J Biol Chem 281: 19019-19028, 2006.

10. Damaj L, le Lorch M, Verkarre V, Werl C, Hubert L, Nihoul-Fékété C, Aigrain Y, de Keyzer Y, Romana SP, Bellanne-Chantelot $\mathrm{C}$, et al: Chromosome 11p15 paternal isodisomy in focal forms of neonatal hyperinsulinism. J Clin Endocrinol Metab 93: 4941-4947, 2008.

11. Inagaki N, Gonoi T, Clement JP IV, Namba N, Inazawa $J$, Gonzalez G, Aguilar-Bryan L, Seino S and Bryan J: Reconstitution of $\mathrm{IK}_{\mathrm{ATP}}$ : an inward rectifier subunit plus the sulfonylurea receptor. Science 270: 1166-1170, 1995.

12. Park S and Terzic A: Quaternary structure of KATP channel SUR2A nucleotide binding domains resolved by synchrotron radiation X-ray scattering. Struct Biol 169: 243-251, 2010.

13. Durell SR and Guy HR: A family of putative Kir potassium channels in prokaryotes. BMC Evol Biol 1: 14, 2001.

14. Aggarwal NT, Shi NQ and Makielski JC: ATP-sensitive potassium currents from channels formed by Kir6 and a modified cardiac mitochondrial SUR2 variant. Channels (Austin) 7: 493-502, 2013.

15. Chan KW, Zhang $\mathrm{H}$ and Logothetis DE: N-terminal transmembrane domain of the SUR controls trafficking and gating of Kir6 channel subunits. EMBO J 22: 3833-3843, 2003.

16. Mori $\mathrm{H}$ and Ito $\mathrm{K}$ : The long alpha-helix of SecA is important for the ATPase coupling of translocation. J Biol Chem 281: 36249-36256, 2006.

17. Baczko I, Husti Z, Lang V, Leprán I and Light PE: Sarcolemmal KATP channel modulators and cardiac arrhythmias. Curr Med Chem 18: 3640-3661, 2011.

18. Nichols CG, Singh GK and Grange DK: $K_{\text {ATP }}$ channels and cardiovascular disease: Suddenly a syndrome. Circ Res 112: 1059-1072, 2013.

19. Nichols CG: $K_{\text {AтP }}$ channels as molecular sensors of cellular metabolism. Nature 440: 470-476, 2006.

20. Haissaguerre M, Chatel S, Sacher F, Weerasooriya R, Probst V, Loussouarn G, Horlitz M, Liersch R, Schulze-Bahr E, Wilde A, et al: Ventricular fibrillation with prominent early repolarization associated with a rare variant of $\mathrm{KCNJ} 8 / \mathrm{K}_{\text {ATP }}$ channel. J Cardiovasc Electrophysiol 20: 93-98, 2009.

21. Fox JE, Magga J, Giles WR and Light PE: Acyl coenzyme A esters differentially activate cardiac and beta-cell adenosine triphosphate-sensitive potassium channels in a side-chain length-specific manner. Metabolism 52: 1313-1319, 2003.

22. John SA, Weiss JN and Ribalet B: ATP sensitivity of ATP-sensitive $\mathrm{K}^{+}$channels: Role of the gamma phosphate group of ATP and the R50 residue of mouse Kir6.2. J Physiol 568: 931-940, 2005.

23. Antcliff JF, Haider S, Proks P, Sansom MS and Ashcroft FM: Functional analysis of a structural model of the ATP-binding site of the $\mathrm{K}_{\text {Атि }}$ channel Kir6.2 subunit. EMBO J 24: 229-239, 2005.

24. Enkvetchakul D and Nichols CG: Gating mechanism of $\mathrm{K}_{\mathrm{ATP}}$ channels: Function fits form. J Gen Physiol 122: 471-480, 2003.

25. Ribalet B, John SA and Weiss JN: Molecular basis for Kir6.2 channel inhibition by adenine nucleotides. Biophys J 84: 266-276, 2003.

26. Trapp S, Haider S, Jones P, Sansom MS and Ashcroft FM: Identification of residues contributing to the ATP binding site of Kir6.2. EMBO J 22: 2903-2912, 2003. 
27. Enkvetchakul D, Jeliazkova I, Bhattacharyya J and Nichols CG: Control of inward rectifier $\mathrm{K}$ channel activity by lipid tethering of cytoplasmic domains. J Gen Physiol 130: 329-334, 2007.

28. Ribalet B, John SA, Xie LH and Weiss JN: ATP-sensitive $\mathrm{K}^{+}$ channels: Regulation of bursting by the sulphonylurea receptor, PIP2 and regions of Kir6.2. J Physiol 571: 303-317, 2006.

29. Pegan S, Arrabit C, Zhou W, Kwiatkowski W, Collins A, Slesinger PA and Choe S: Cytoplasmic domain structures of Kir2.1 and Kir3.1 show sites for modulating gating and rectification. Nat Neurosci 8: 279-287, 2005.

30. Hund TJ and Mohler PJ: Differential roles for SUR subunits in $\mathrm{K}_{\text {ATP }}$ channel membrane targeting and regulation. Am J Physiol Heart Circ Physiol 300: H33-H35, 2011.

31. Cui N, Kang Y, He Y, Leung YM, Xie H, Pasyk EA, Gao X, Sheu L, Hansen JB, Wahl P, et al: H3 domain of syntaxin 1A inhibits $\mathrm{K}_{\mathrm{ATP}}$ channels by its actions on the sulfonylurea receptor 1 nucleotide-binding folds-1 and -2. J Biol Chem 279: 53259-53265, 2004.

32. Ueda K, Inagaki $\mathrm{N}$ and Seino S: MgADP antagonism to $\mathrm{Mg} 2+-$ independent ATP binding of the sulfonylurea receptor SUR1. J Biol Chem 272: 22983-22986, 1997.

33. Babenko AP and Bryan J: Sur domains that associate with and gate $\mathrm{K}_{\text {атр }}$ pores define a novel gatekeeper. J Biol Chem 278: 41577-41580, 2003.

34. Tsounapi P, Satio M, Dimitriadis F, Kitatani K, Kinoshita Y, Shomori K, Takenaka A and Satoh K: The role of K ATP channels on ischemia-reperfusion injury in the rat testis. Life Sci 90: 649-656, 2012

35. Glukhov AV, Flagg TP, Fedorov VV, Efimov IR and Nichols CG: Differential K (ATP) channel pharmacology in intact mouse heart. J Mol Cell Cardiol 48: 152-160, 2010.

36. Glukhov AV, Uchida K, Efimov IR and Nichols CG: Functional roles of $\mathrm{K}_{\text {Атр }}$ channel subunits in metabolic inhibition. J Mol Cell Cardiol 62: 90-98, 2013.

37. Marinovic J, Ljubkovic M, Stadnicka A, Bosnjak ZJ and Bienengraeber M: Role of sarcolemmal ATP-sensitive potassium channel in oxidative stress-induced apoptosis: Mitochondrial connection. Am J Physiol Heart Circ Physiol 294: H1317-H1325, 2008 .

38. Zhang DM, Chai Y, Erickson JR, Brown JH, Bers DM and Lin YF: Intracellular signalling mechanism responsible for modulation of sarcolemmal ATP-sensitive potassium channels by nitric oxide in ventricular cardiomyocytes. J Physiol 592: 971-990, 2014

39. Voitychuk OI, Strutynskyi RB, Yagupolskii LM, Tinker A, Moibenko OO and Shuba YM: Sarcolemmal cardiac K(ATP) channels as a target for the cardioprotective effects of the fluorine-containing pinacidil analogue, flocalin. $\mathrm{Br}$ Pharmacol 162: 701-711, 2011

40. Xie C, Hu J, Motloch LJ, Karam BS and Akar FG: The classically cardioprotective agent diazoxide elicits arrhythmias in type 2 diabetes mellitus. J Am Coll Cardiol 66: 1144-1156, 2015.

41. Liu Y, Ren G, O'Rourke B, Marban E and Seharaseyon J: Pharmacological comparison of native mitochondrial K (ATP) channels with molecularly defined surface K (ATP) channels. Mol Pharmacol 59: 225-230, 2001.

42. Suzuki M, Sasaki N, Miki T, Sakamoto N, Ohmoto-Sekine Y, Tamagawa M, Seino S, Marbán E and Nakaya H: Role of sarcolemmal K(ATP) channels in cardioprotection against ischemia/reperfusion injury in mice. J Clin Invest 109: 509-516, 2002.

43. Foster DB, Rucker JJ and Marban E: Is Kir6.1 a subunit of mitoK(ATP)? Biochem Biophys Res Commun 366: 649-656, 2008

44. Pu JL, Ye B, Kroboth SL, McNally EM, Makielski JC and Shi NQ: Cardiac sulfonylurea receptor short form-based channels confer a glibenclamide-insensitive $\mathrm{K}_{\text {АTP }}$ activity. J Mol Cell Cardiol 44 188-200, 2008

45. Mykytenko J, Reeves JG, Kin H, Wang NP, Zatta AJ, Jiang R, Guyton RA, Vinten-Johansen J and Zhao ZQ: Persistent beneficial effect of postconditioning against infarct size: Role of mitochondrial K(ATP) channels during reperfusion. Basic Res Cardiol 103: 472-484, 2008.

46. Hensley N, Dietrich J, Nyhan D, Mitter N, Yee MS and Brady M: Hypertrophic cardiomyopathy: a review. Anesth Analg 120: 554-569, 2015.

47. Teekakirikul P, Padera RF, Seidman JG and Seidman CE: Hypertrophic cardiomyopathy: Translating cellular cross talk into therapeutics. J Cell Biol 199: 417-421, 2012.

48. Vakrou S and Abraham MR: Hypertrophic cardiomyopathy: a heart in need of an energy bar? Front Physiol 19: 309, 2014
49. Sodder VH, Bowie LD and Cameron JS: Trypsin alters ATP sensitivity of $\mathrm{K}_{\text {ATP }}$ channels in control and hypertrophied myocytes. Eur J Pharmacol 315: 115-118, 1996.

50. Rajesh KG, Sasaguri S, Suzuki R, Xing Y and Maeda H: Ischemic preconditioning prevents reperfusion heart injury in cardiac hypertrophy by activation of mitochondrial $\mathrm{K}_{\mathrm{ATP}}$ channels. Int J Cardiol 96: 41-49, 2004

51. Xia Y, Rajapurohitam V, Cook MA and Karmazyn M: Inhibition of phenylephrine induced hypertrophy in rat neonatal cardiomyocytes by the mitochondrial $\mathrm{K}_{\mathrm{ATP}}$ channel opener diazoxide. J Mol Cell Cardiol 37: 1063-1067, 2004.

52. Yuan F, Brandt NR, Pinto JM, Wasserlauf BJ, Myerburg RJ and Bassett AL: Hypertrophy decreases cardiac $\mathrm{K}_{\text {ATp }}$ channel responsiveness to exogenous and locally generated (glycolytic) ATP. J Mol Cell Cardiol 29: 2837-2848, 1997.

53. Stoller D, Kakkar R, Smelley M, Chalupsky K, Earley JU, Shi NQ, Makielski JC and McNally EM: Mice lacking sulfonylurea receptor 2 (SUR2) ATP-sensitive potassium channels are resistant to acute cardiovascular stress. J Mol Cell Cardiol 43: 445-454, 2007.

54. Shimokawa J, Yokoshiki $\mathrm{H}$ and Tsutsui $\mathrm{H}$ : Impaired activation of ATP-sensitive $\mathrm{K}^{+}$channels in endocardial myocytes from left ventricular hypertrophy. Am J Physiol Heart Circ Physiol 293: H3643-H3649, 2007.

55. Gao S, Long CL, Wang RH and Wang H: K (ATP) activation prevents progression of cardiac hypertrophy to failure induced by pressure overload via protecting endothelial function. Cardiovasc Res 83: 444-456, 2009

56. Hu X, Xu X, Huang Y, Fassett J, Flagg TP, Zhang Y, Nichols CG, Bache RJ and Chen Y: Disruption of sarcolemmal ATP-sensitive potassium channel activity impairs the cardiac response to systolic overload. Circ Res 103: 1009-1017, 2008.

57. Sanbe A: Dilated cardiomyopathy: A disease of the myocardium. Biol Pharm Bull 36: 18-22, 2013.

58. Luk A, Ahn E, Soor GS, Soor GS and Butany J: Dilated cardiomyopathy: a review. J Clin Pathol 62: 219-225, 2009.

59. Bienengraeber M, Olson TM, Selivanov VA, Kathmann EC, O'Cochlain F, Gao F, Karger AB, Ballew JD, Hodgson DM, Zingman LV, et al: ABCC9 mutations identified in human dilated cardiomyopathy disrupt catalytic $\mathrm{K}_{\text {ATP }}$ channel gating. Nat Genet 36: 382-387, 2004.

60. Farid TA, Nair K, Massé S, Azam MA, Maguy A, Lai PF, Umapathy K, Dorian P, Chauhan V, Varró A, et al: Role of $\mathrm{K}_{\mathrm{ATP}}$ channels in the maintenance of ventricular fibrillation in cardiomyopathic human hearts. Circ Res 109: 1309-1318, 2011.

61. Grover GJ and Garlid KD: ATP-Sensitive potassium channels A review of their cardioprotective pharmacology. J Mol Cell Cardiol 32: 677-695, 2000

62. Yamada S, Nelson TJ, Crespo-Diaz RJ, Perez-Terzic C, Liu XK, Miki T, Seino S, Behfar A and Terzic A: Embryonic stem cell therapy of heart failure in genetic cardiomyopathy. Stem Cells 26: 2644-2653, 2008

63. Cheung CY, Tso AW, Cheung BM, Xu A, Fong $\mathrm{CH}$, Ong KL, Law LS, Wat NM, Janus ED, Sham PC, et al: The KCNJ11 E23 K polymorphism and progression of glycaemia in Southern Chinese: A long-term prospective study. PLoS One 6: e28598, 2011.

64. Xi HL, Liu JF, Li L and Wan J: Relationship between dilated cardiomyopathy and the E23K and I337V polymorphisms in the Kir6.2 subunit of the $\mathrm{K}_{\text {ATP }}$ channel. Genet Mol Res 12: 4383-4392, 2013

65. Kalogeropoulos A, Georgiopoulou V, Kritchevsky SB, Psaty BM, Smith NL, Newman AB, Rodondi N, Satterfield S, Bauer DC, Bibbins-Domingo K, et al: Epidemiology of incident heart failure in a contemporary elderly cohort: The health, aging and body composition study. Arch Intern Med 169: 708-715, 2009

66. Elrod JW and Molkentin JD: Physiologic functions of cyclophilin $\mathrm{D}$ and the mitochondrial permeability transition pore. Circ J 77: 1111-1122, 2013.

67. Rousou AJ, Ericsson M, Federman M, Levitsky S and McCully JD: Opening of mitochondrial $\mathrm{K}_{\text {ATP }}$ channels enhances cardioprotection through the modulation of mitochondrial matrix volume, calcium accumulation and respiration. Am J Physiol Heart Circ Physiol 287: H1967-H1976, 2004.

68. McPherson R and Davies RW: Inflammation and coronary artery disease: Insights from genetic studies. Can J Cardiol 28: 662-666, 2012 
69. SafranowK,Dziedziejko V,Rzeuski R,CzyzyckaE,Wojtarowicz A Bińczak-Kuleta A, Jakubowska K, Olszewska M, Ciechanowicz A, Kornacewicz-Jach Z, et al: Plasma concentrations of TNF-alpha and its soluble receptors sTNFR1 and sTNFR2 in patients with coronary artery disease. Tissue Antigens 74: 386-392, 2009.

70. Zhou F, Yao HH, Wu JY, Ding JH, Sun T and Hu G: Opening of microglial K(ATP) channels inhibits rotenone-induced neuroinflammation. J Cell Mol Med 12: 1559-1570, 2008.

71. Kaspar RW, Allen HD and Montanaro F: Current understanding and management of dilated cardiomyopathy in Duchenne and Becker muscular dystrophy. J Am Acad Nurse Pract 21: 241-249, 2009.

72. Townsend D, Yasuda S and Metzger J: Cardiomyopathy of Duchenne muscular dystrophy: Pathogenesis and prospect of membrane sealants as a new therapeutic approach. Expert Rev Cardiovasc Ther 5: 99-109, 2007.

73. Graciotti L, Becker J, Granata AL, Procopio AD, Tessarollo L and Fulgenzi G: Dystrophin is required for the normal function of the cardio-protective K(ATP) channel in cardiomyocytes. PLoS One 6: e27034, 2011

74. Pappachan JM, Varughese GI, Sriraman R and Arunagirinathan G: Diabetic cardiomyopathy: Pathophysiology, diagnostic evaluation and management. World J Diabetes 4: 177-189, 2013.

75. Gloyn AL, Weedon MN, Owen KR, Turner MJ, Knight BA, Hitman G, Walker M, Levy JC, Sampson M, Halford S, et al: Large-scale association studies of variants in genes encoding the pancreatic beta-cell $\mathrm{K}_{\mathrm{ATP}}$ channel subunits Kir6.2 (KCNJ11) and SUR1 (ABCC8) confirm that the KCNJ11 E23K variant is associated with type 2 diabetes. Diabetes 52: 568-572, 2003.
76. Mannikko R, Flanagan SE, Sim X, Segal D, Hussain K, Ellard S, Hattersley AT and Ashcroft FM: Mutations of the same conserved glutamate residue in NBD2 of the sulfonylurea receptor 1 subunit of the $\mathrm{K}_{\text {ATP }}$ channel can result in either hyperinsulinism or neonatal diabetes. Diabetes 60: 1813-1822, 2011.

77. Fancher IS, Dick GM and Hollander JM: Diabetes mellitus reduces the function and expression of ATP-dependent $\mathrm{K}(+)$ channels in cardiac mitochondria. Life Sci 92: 664-668, 2013.

78. Chen ZC, Cheng YZ, Chen LJ, Cheng KC, Li Y and Cheng J: Increase of ATP-sensitive potassium (K(ATP)) channels in the heart of type-1 diabetic rats. Cardiovasc Diabetol 11: 8, 2012.

79. Li GS, Wang F, Kang D and Li C: Keshan disease: An endemic cardiomyopathy in China. Hum Pathol 16: 602-609, 1985.

80. Lei C, Niu X, Ma X and Wei J: Is selenium deficiency really the cause of Keshan disease? Environ Geochem Health 33: 183-188, 2011.

81. Chen J: An original discovery: Selenium deficiency and Keshan disease (an endemic heart disease). Asia Pac J Clin Nutr 21: 320-326, 2012

82. Liu ZW, Niu XL, Chen KL, Xing YJ, Wang X, Qiu C and Gao DF: Selenium attenuates adriamycin-induced cardiac dysfunction via restoring expression of ATP-sensitive potassium channels in rats. Biol Trace Elem Res 153: 220-228, 2013.

83. Pereira SP, Pereira GC, Pereira CV, Carvalho FS, Cordeiro MH, Mota PC, Ramalho-Santos J, Moreno AJ and Oliveira PJ: Dioxin-induced acute cardiac mitochondrial oxidative damage and increased activity of ATP-sensitive potassium channels in Wistar rats. Environ Pollut 180: 281-290, 2013. 